\title{
A note on "Why does the Ballenas Channel have the coldest SST in the Gulf of California?"
}

\author{
S. G. Marinone ${ }^{1}$ \\ Received 26 October 2006; revised 27 November 2006; accepted 8 December 2006; published 20 January 2007.
}

[1] A three-dimensional nonlinear baroclinic model is used to verify the circulation in the Ballenas Channel (Gulf of California) deduced from observations, which concluded that the cold SST of the channel is due to the deep inflow of water over the sills at both ends of the channel; this convergence at depth would lead to upwelling (divergence) in the upper layers, and to surface outflow through both ends. Here it is reported that the deep flow from the south does enters into the channel but not that from the north. The deep inflow returns back mainly along the surface through the same southern end of the channel and a small fraction flows out through the northern end of the channel and between Ángel de la Guarda and San Lorenzo Islands. The bottom flow that enters through San Esteban sill does not go all the way along Tiburon and Delfin basins and into Ballenas Channel through the northern sill; instead, it returns in the intermediate and surface layers after mixing in those basins. Citation: Marinone, S. G. (2007), A note on "Why does the Ballenas Channel have the coldest SST in the Gulf of California?', Geophys. Res. Lett., 34, L02607, doi:10.1029/ 2006 GL028589.

\section{Introduction}

[2] Recently López et al. [2006] (hereinafter referred to as LCA) put forward an explanation for the year-round low SST in Ballenas Channel (BC, Gulf of California, Figure 1), as compared to the surrounding region. Their result comes from direct observations at the San Esteban (SE), San Lorenzo (SL), and North Ballenas Channel (NBC) sills, where different processes (tidal pumping and mean currents) produce a deep inflow to the $\mathrm{BC}$ and an outflow in the upper levels through the SL and NBC sills. They argue that the upwelling associated to the surface divergence explains the low SST of the area.

[3] The deep inflow through the SL and SE sills have been reported before by means of hydrographic data [Bray, 1988], current observations [Badan-Dangon et al., 1991] and numerical models [Marinone and Lavin, 2003]. However, the circulation into and out of the Ballenas Channel, as suggested by LCA, has not been described. The objective of this communication is to verify the circulation scheme proposed by LCA, which was deduced only from (three) vertical moorings over the sills, by means of a threedimensional hydrodynamic numerical model of the Gulf

\footnotetext{
${ }^{1}$ Department of Physical Oceanography, Centro de Investigación Científica y de Educación Superior de Ensenada, Tijuana, Mexico.
}

of California. The model allows transport calculations over the entire cross sections that include the sills.

\section{Numerical Model and Analyses}

[4] The numerical model used is the three-dimensional baroclinic Hamburg Shelf Ocean Model (HAMSOM) developed by Backhaus [1985]. The model is described in detail for the Gulf of California by Marinone [2003] and Mateos et al. [2006], and in general references therein. Its domain has a mesh size of $2.5^{\prime} \times 2.5^{\prime}(\sim 3.9 \times 4.6 \mathrm{~km})$ in the horizontal and 12 layers in the vertical with nominal lower levels at 10, 20, 30, 60, 100, 150, 200, 250, 350, 600, 1000 and $4000 \mathrm{~m}$. The model equations are solved semiimplicitly with fully prognostic temperature and salinity fields, thus allowing time-dependent baroclinic motions.

[5] The model is forced with tides, climatological winds (a simple up- and down-gulf annual sinusoid), climatological hydrography at the mouth of the gulf, and climatological heat and fresh water fluxes at the air-sea interface. As shown by Marinone [2003], the model adequately reproduces the main seasonal signals of surface temperature, heat balance, tidal elevation and surface circulation in the northern Gulf of California as reported by Lavin et al. [1997]. However, since the model grid size is larger than the topographic scales of the sills, the model velocities are weaker than in the observations, which are channeled in the narrow canyons, and by continuity result in stronger currents. It is anticipated that these narrow "deep channels" due to the model resolution result in shallower sills.

[6] A one-year model simulation is used and the instantaneous currents and density fields are split into high and low frequency variability. This procedure is intended to evaluate the tidal pumping mechanism invoked by LCA, which consist of calculating the transport of water below and above a given isopycnal, considering the vertical excursion of the latter. Although the model currents are smaller compared to the observations in the exact sill positions, the transports are comparable. However, the model should produce a mean/residual circulation due to tidal rectification [Marinone, 2003], whose magnitude is comparable to that proposed by LCA, which permits the verification of the proposed circulation. Transport across different cross sections (see Figure 1) will be calculated: Section I includes NBC sill, Section II is just west of SL sill, Section III includes SE sill, and sections IV, V and VI are included to check continuity. Section VII is also included to calculate the flow that enters BC (with sections I and II). Note that these calculations give the total transport in the sections, which would be compared to that obtained by 

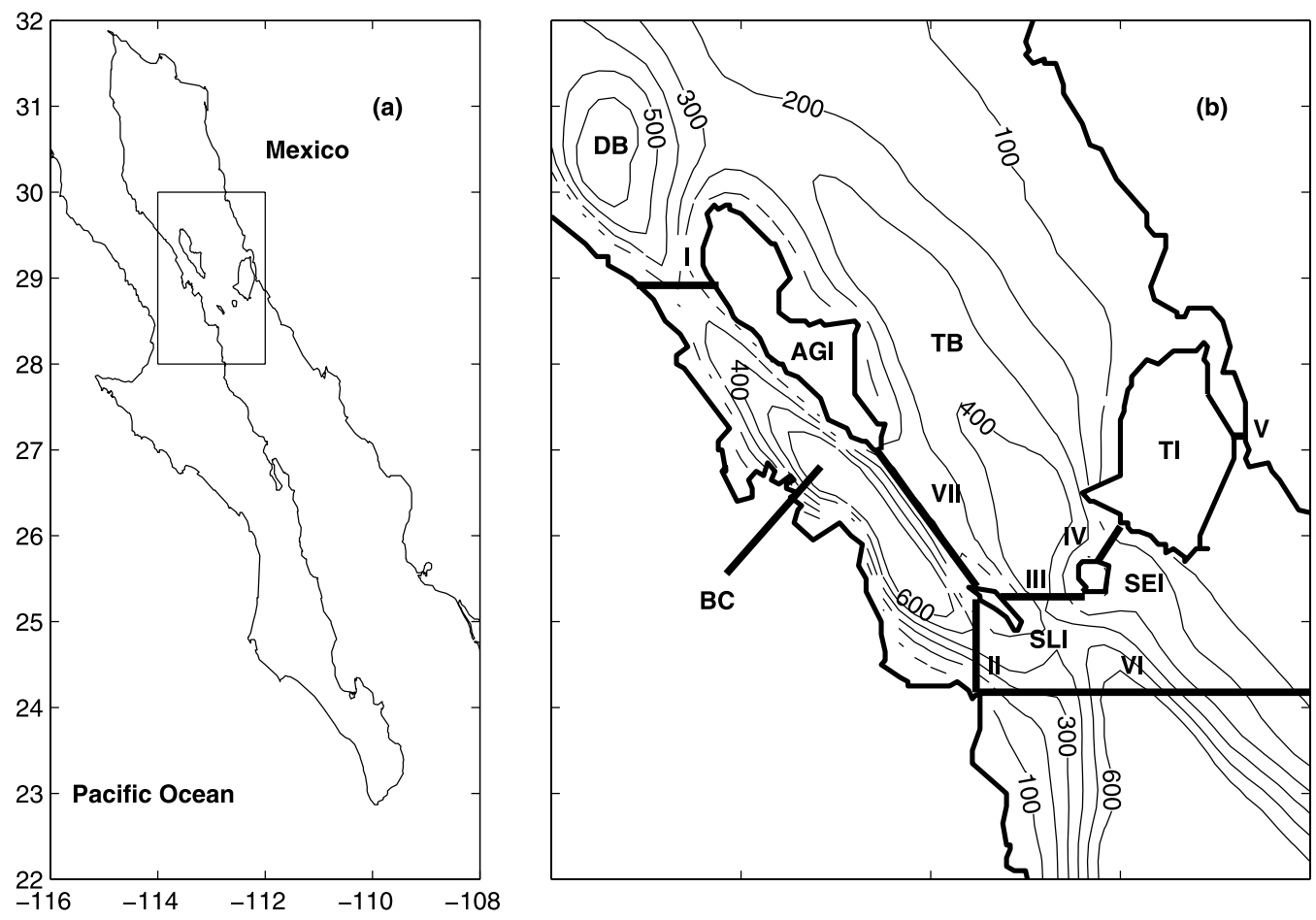

Figure 1. (a) Location of the Gulf of California. (b) Bathymetry (m) of the study area. The lines labeled from I-VII are the cross-sections where some results are shown. AGI, TI, SEI, and SLI stand for Ángel de la Guarda, Tiburón, San Esteban, and San Lorenzo islands, respectively. The North Ballenas (NBC), and San Esteban (SE) sills are located on sections I and III, respectively. San Lorenzo (SL) sill is located to the west of section II. BC stands for Ballenas/Salsipuedes channel, and DB and TB for Delfiacute;n and Tiburón basins, respectively.

LCA, which were obtained from a single vertical array in each section.

\section{Results}

[7] The deep flow convergence and the surface flow diverging circulation proposed by LCA has the intention of explaining the year-round colder SST of BC as compared to the rest of the area. They were limited to $6-8$ months of observations; however, with the model a full year simulation can provide the full seasonal cycle of the circulation with the "tidal pumping process" included, as the numerical model is fully baroclinic and nonlinear. Figure 2 shows the annual average currents for the model layers $3,5,8$, and 10 for the indicated depths (the other layers behave similarly and are not shown); these layers capture the vertical shear of the currents. The first result is that, as previously reported by Marinone [2003] and Marinone and Lavin [2003] (same model), the mean flow is up-gulf at depth and down-gulf at the surface through sections II and III where both southern sills are located (section II captures what passes through SL). The up-gulf deep current that passes through SE flows along the east side of AGI up to the northern tip of the island, where an anticlockwise gyre is produced.

[8] What is not really clear from Figure 2, by inspecting the horizontal flows, is whether the total flow (in the annual average sense) that comes into the $\mathrm{BC}$ is actually from the deep part of the water column, and whether it comes in through both ends of the channel. A blow-up of the horizontal flow in the NBC (Figure 3) shows eddies close to the sill but no appreciable net flow into BC. These eddies are as wide as the channel, and exhibit large vertical and horizontal shears. For this reason we calculated the total transports through the different sections and evaluated those transports in a similar manner as LCA did.

[9] Table 1 shows the annual mean transports integrated across the different sections of the study area. These transports were calculated by computing the volume of water that flows above and below a given isopycnal (in the same manner as LCA did; also, different isopycnals were used but the results for the different choices did not change much). It is notable that in NBC the transports above and below the isopycnal are both up-gulf and small (compared to the transports of SL and SE sills); this is in direct contradiction to the LCA result. Here it is found that, on the annual average, the flow that comes into the $\mathrm{BC}$ is mainly at depth through the southern end (SL). LCA report a mean twolayer flow over NBC sill (for their 6 month period of observation). However, these eddies near the sill (Figure 3) cause the cancellation of the transport when integrated laterally, leading to the disagreement with the observations of LCA. In particular, the year-mean water balance for BC is as follows: inflow is mainly through the lower part of section II (SL) with $0.124 \mathrm{~Sv}$, while outflow occurs over the rest of the water column on the same section and in all the water column of Section I (NBC). Also, between Ángel de la Guarda Island (AGI) and San Lorenzo Island (SLI, section VII which is shallow, $\sim 240 \mathrm{~m}$ ) a small fraction of the total transport enters and exits the $\mathrm{BC}$ at the lower and upper part of the water column, respectively.

[10] The gulf's circulation, to the north and east of AGI, has a strong seasonal variation [Lavin et al., 1997]: 

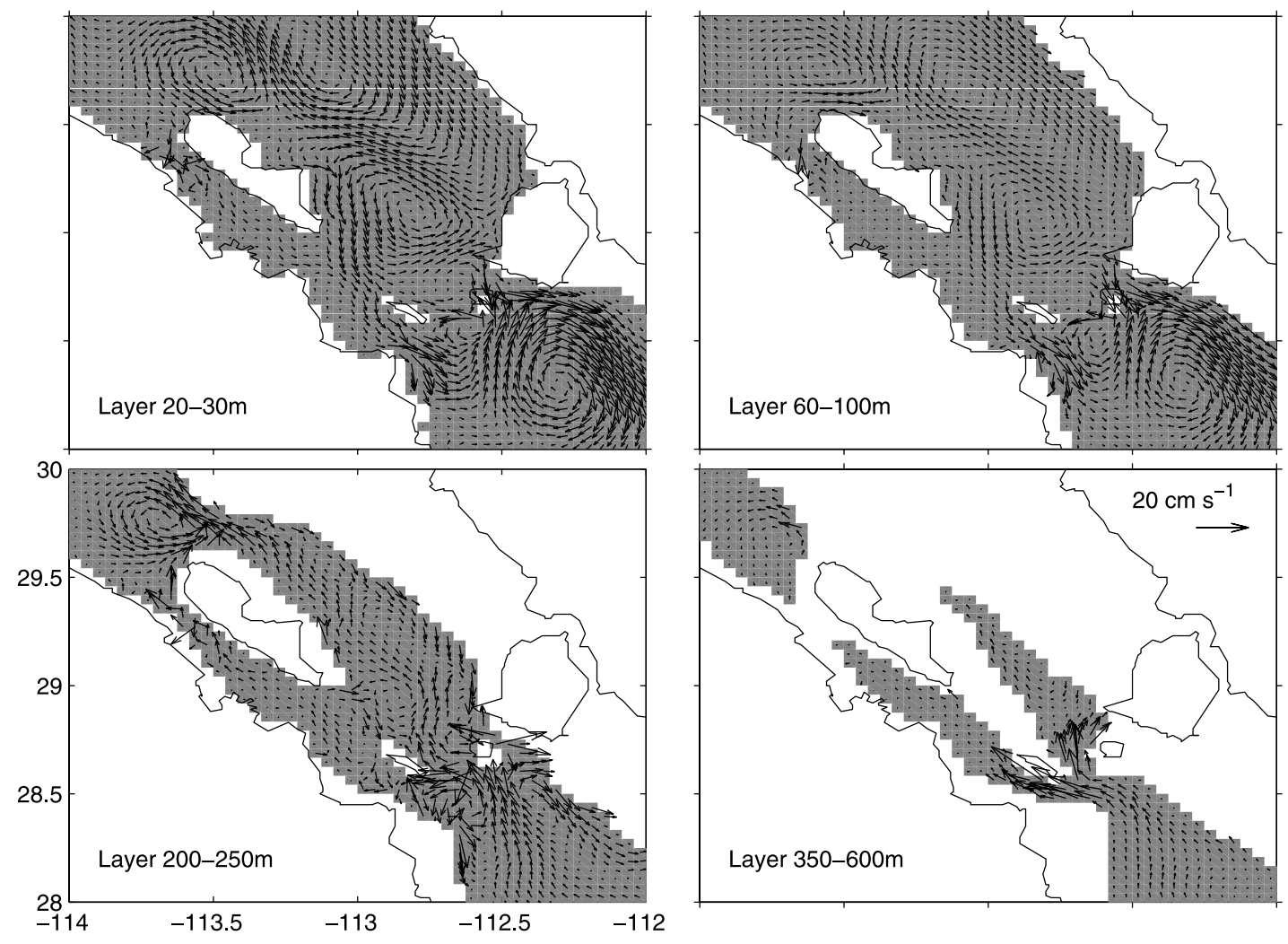

Figure 2. Annual averaged currents of the indicated modeled layers.
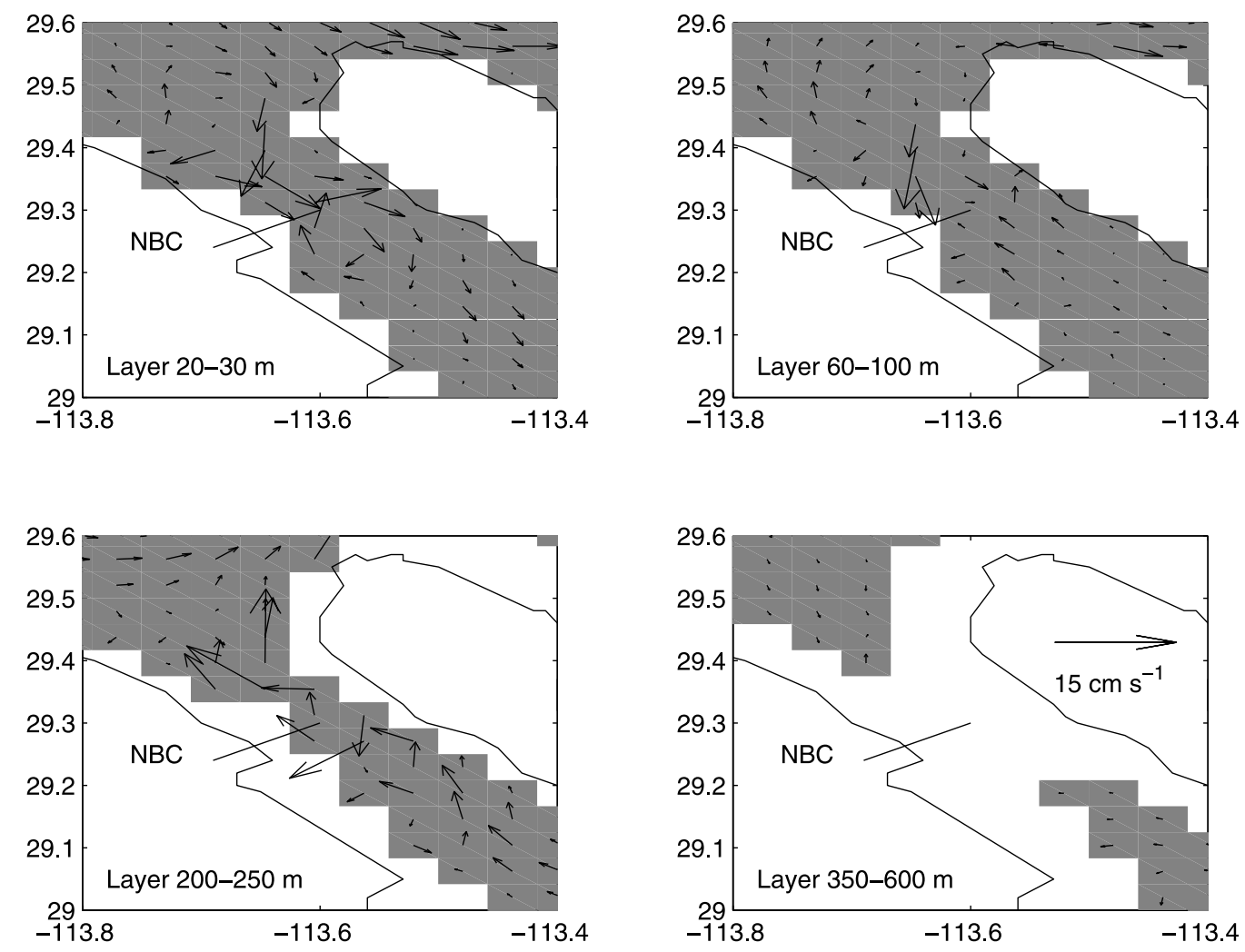

Figure 3. Annual averaged currents of the indicated modeled layers. The area is a zoom of Figure 2 into the northern entrance of Ballenas Channel with all vectors shown. Note the position of the North Ballenas Channel sill which blocks flow at the $350 \mathrm{~m}$ depth. 
Table 1. Annual Averaged Transports Over and Below a Moving Isopycnal and Net Through the Indicated Sections ${ }^{\mathrm{a}}$

\begin{tabular}{clrrr}
\hline Section $^{\mathrm{b}}$ & Reference & \multicolumn{1}{c}{ Over } & Below & Net Transport \\
\hline I & NBC & 0.010 & 0.018 & 0.028 \\
II & SL & 0.101 & -0.124 & -0.022 \\
III & SE & -0.033 & 0.186 & 0.153 \\
IV & SEI-TI & -0.138 & -0.038 & -0.175 \\
V & TI-SON & -0.001 & 0.000 & -0.001 \\
VII & SLI-AGI & 0.018 & -0.013 & 0.004 \\
VI & Control & -0.280 & 0.278 & -0.002 \\
\hline
\end{tabular}

${ }^{a}$ Transport is measured in $\mathrm{Sv}=1 \times 10^{6} \mathrm{~m}^{3} \mathrm{~s}^{-1}$. Isopycnal is $\sigma_{\mathrm{s}, \mathrm{t}, \mathrm{p}}=27$. See Figure 1 for section locations and acronyms. SON stands for Sonora in mainland Mexico.

${ }^{b}$ Note that for sections I, III, IV, V, and VI positive sign means up-gulf. For sections II and VII positive sign is to the E and SW, respectively, and mean out and into BC, respectively. Section VI is shown just for control purposes (what goes into the gulf must go out; the difference is $-0.002 \mathrm{SV}$, an error $\ll 1 \%$ with respect of the any up or down gulf transport). For example, what flows through section VI $(-0.002 \mathrm{~Sv})$ should flow up-gulf through section II, II, IV, and V, then the flow is the sum of $(-\mathrm{II}+\mathrm{III}+$ IV + IV $)=-0.001 \mathrm{~Sv}$, again a relative error less than $1 \%$ compared to the largest of the net transports of the involved sections. For BC, it is I + $\mathrm{II}-\mathrm{VII}=0.002 \mathrm{~Sv}$.

cyclonic during summer and anticyclonic during winter. To check whether this reversal of the circulation can change the transport around the $\mathrm{BC}$, the calculations were repeated for the months of February and August, when the northern gyres are well developed. The results (see Table 2) are qualitatively the same as in the annual average, changing only in the intensity: the deep flow is more intense during winter.

[11] LCA report transports at-depth of $0.09 \mathrm{~Sv}$ in both SL and SE sills, which are of the same order as the annual average found here, i.e., 0.12 and $0.19 \mathrm{~Sv}$, respectively. The agreement is acceptable as their calculations were made using a single ADCP at each sill and a series of SBE Microcats to measure temperature and conductivity to calculate density in one vertical array; from these data they assume that there is no lateral variation of the velocity and the position of the isopycnal. Actually the model shows large horizontal shear as can be seen in Figure 4 for the annual averaged flow. The shear is large even though it is that of the annual averaged current. At the NBC, LCA did not have hydrographic measurements and LCA only calculated the mean velocities at different depths.

[12] As the circulation proposed by LCA involves a vertical movement of water, the vertical velocity in the model was calculated for the $\mathrm{BC}$ area. The calculations were made for the whole year and for February and August only. The time averaged vertical velocity was spatially averaged over the $\mathrm{BC}$ region (the model surface area is $2.3 \times 10^{9} \mathrm{~m}^{2}$ and a mean depth of $418 \mathrm{~m}$ ). For the lower levels the velocities range from 2.2 to $3.5 \mathrm{~m} \mathrm{day}^{-1}$. Assuming that the inflow to the BC is only from SL with an annual average of $0.124 \mathrm{~Sv}$, the ratio of this figure to the total surface area implies a vertical velocity of $4.5 \mathrm{~m} \mathrm{day}^{-1}$, which is a little higher than the direct model values. For the February and August cases the results were similar.

\section{Discussion and Conclusion}

[13] The calculations shown were all obtained directly from the residual currents obtained by applying a low pass filter to the instantaneous currents. The filter passes about $50 \%$ of the amplitude at 0.3 cycle day $^{-1}$ and $95 \%$ of the amplitude at 0.08 cycle day $^{-1}$, while it reduces to less than $1 \%$ the diurnal and semi-diurnal amplitudes [Yao et al., 1982]. LCA calculated the transport through the sills due to the mean current below the mean depth of a selected isopycnal. Then calculated the time averaged transport of the instantaneous flow below the instantaneous position of the given isopycnal; the difference of these averaged quantities they defined as "tidal pumping." In the case of this paper, the low frequency or residual currents captures all the tidal effect and it was checked by repeating the calculations with the instantaneous current and density vertical positions. The time average of the quantity is the same as that obtained with the residual fields (this was checked with the monthly computations), however the calculations are much faster than with the instantaneous model output (e.g., the latter require hourly output while for the residual only daily values are necessary).

[14] The result obtained here is in partial agreement with that of LCA. They obtain a deep inflow through SL sill to the $\mathrm{BC}$ as obtained here. Also they obtain an up-gulf deep inflow through the deeper SE sill, as it was also obtained here, however they "imply" that this deep inflow goes to $\mathrm{BC}$ surrounding AGI and then entering the BC through the northern sill (NBC). There they have measured a mean deep flow into BC. Only this deep flow over NBC is not found in this work.

[15] The model, obviously, has many limitations but "a possible explanation for the discrepancy" is that a "tidal pumping" process in the observations of LCA is present and opposite to the mean flow (as they obtain in SE) which produces a zero net inflow to the channel, as reported, with only 20 days of observations, by Badan-Dangon et al. [1991]. It is also possible that the model mean circulation, because of the model resolution, is produced by simple tidal rectification (and other processes) without being clear that the "tidal pumping" (which is the correlation of the fluctuating velocity and depth of the isopycnals) is dominating and, as LCA mention, transforms/converges into the general circulation. Also, and maybe more important, the model resolution in this particular sill "sees" a much shallower sill (the deepest modeled layer is $250-350 \mathrm{~m}$ there), and then the climbing of deep water turns to be

Table 2. Same as Table 1 for February and August

\begin{tabular}{llrrr}
\hline Section & Reference & Over & Below & Net Transport \\
\hline & & February & & \\
I & NBC & 0.032 & 0.029 & 0.061 \\
II & SL & 0.109 & -0.099 & 0.010 \\
III & SE & -0.066 & 0.232 & 0.165 \\
IV & SEI-TI & -0.121 & -0.020 & -0.140 \\
V & IT-SON & -0.018 & 0.000 & -0.018 \\
VII & ISL-AGI & 0.077 & -0.007 & 0.070 \\
VI & Control & -0.351 & 0.347 & -0.003 \\
& & & & \\
& & August & & -0.050 \\
I & NBC & -0.054 & 0.005 & -0.025 \\
II & SL & 0.057 & -0.082 & 0.176 \\
III & SE & 0.094 & 0.082 & -0.220 \\
IV & SEI-TI & -0.194 & -0.026 & 0.018 \\
V & TI-SON & 0.018 & 0.000 & -0.076 \\
VII & ISL-AGI & -0.049 & -0.027 & -0.001 \\
VI & Control & -0.095 & 0.093 & \\
\hline
\end{tabular}



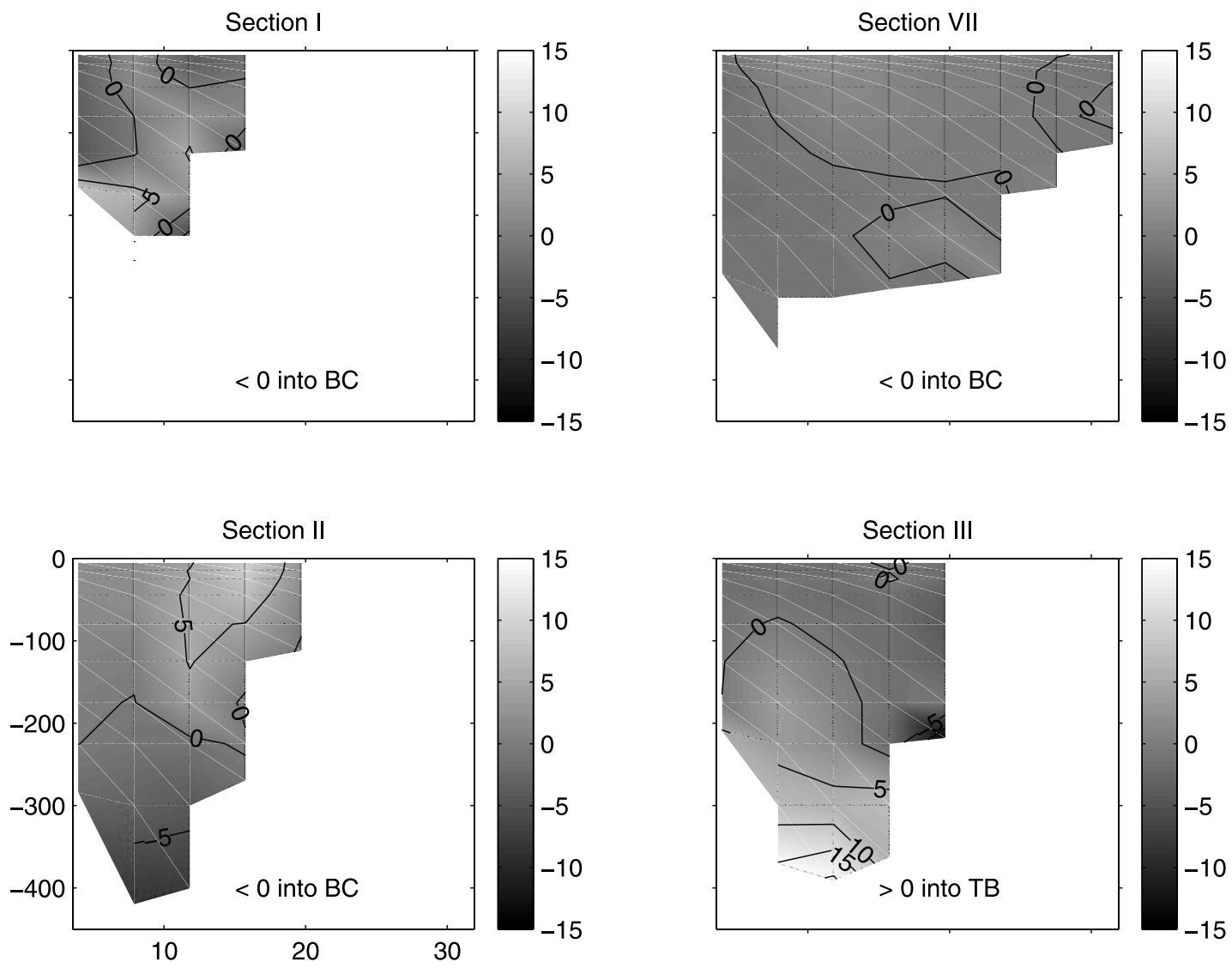

Figure 4. Annual averaged normal velocity $\left(\mathrm{cm} \mathrm{s}^{-1}\right)$ to the indicated sections (see Figure 1). Vertical and horizontal axes are in $\mathrm{m}$ and $\mathrm{km}$, respectively.

impossible in the model and the flow is re-circulated over Delfín Basin as can be appreciated in Figure 2 (layer 200$250 \mathrm{~m})$. Over the part of water column where the observations of LCA were made, the model correctly produces flow out of the channel.

[16] With this level of resolution, the model has a reasonable agreement with the observed circulation pattern proposed by LCA which would be improved when a better bathymetry is available. The obtained three dimensional circulation can be exploited to investigate and understand, for example, the surface enrichment of $\mathrm{BC}$ by nutrients brought to the photic zone by this upwelling process; the $\mathrm{BC}$ is known to be a highly productive area. The deep flow produced over the sills is controlled by the tides: without tides this circulation pattern is not produced by the model. The mechanism is similar to that acting in some "silled" estuarine fjords (e.g. Indian Arm, Strait of Georgia, both in Canada [LeBlond et al., 1991; de Young and Pond, 1988]) where the tidal currents over a sill block the saltier and heavy flow upstream during spring tides (when strong mixing is produced), while during neap tides (when the mechanical energy is weakest) a two layers system is obtained and the denser deep flow drains to the deep basins [Griffin and LeBlond, 1990].

[17] In any case, it is clear that just with the inflow from SL sill the cooler SST of Ballenas Channel can be explained. Our modeled scenario is shown in Figure 5. The largest transports are at depth through SL and SE sills (sections II and III, respectively). The flow over SL sill fills Ballenas Channel, mixes and returns through the upper levels. The flow over SE sill fills Tiburon Basin passing through another sill at the northern end of Tiburón basin,

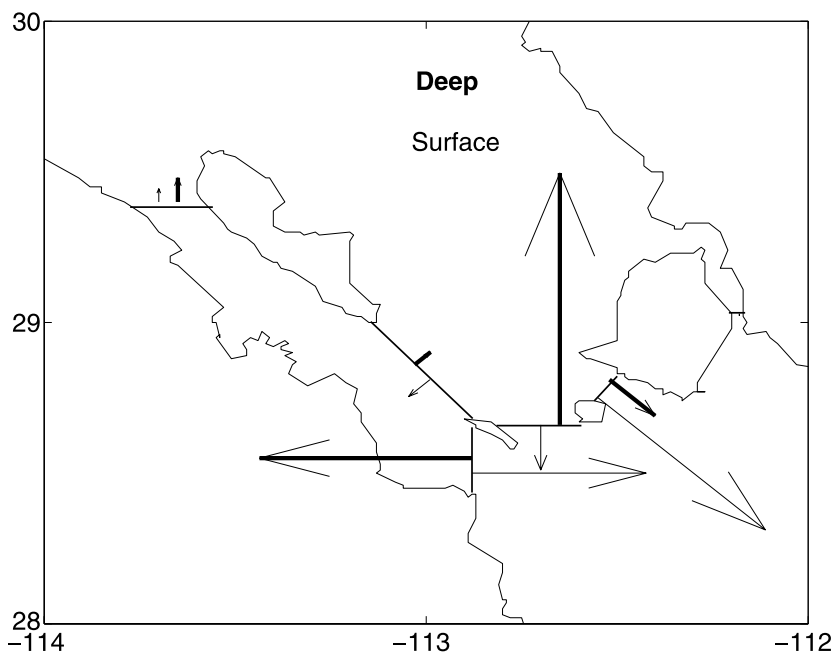

Figure 5. Schematic diagram of the annual average transports through the different sections around the island region in the Gulf of California. Thick arrows correspond to deep flow and thin arrows to surface flow. The actual values of the transports are those of Table 1. 
where López and Garcia [2003] also reported a northward bottom current which then in turn fills Delfín Basin (DB), as found here too (see Figures 2 and 3). The "model NBC" which, as mentioned, is shallower in the model, blocks the deep current (against the proposed circulation of LCA) and returns without entering to $\mathrm{BC}$. Then, the outflow is again basically through the same southern sections. The net transport in the NBC is small and out of $\mathrm{BC}$ throughout the entire water column.

[18] Finally, the fact that the deep up-gulf flow east of AGI reaches DB and mixes and returns through the upper levels implies an upwelling process similar to that in BC. This is true in the model where similar vertical velocities, as reported above, were obtained. Also high levels of nutrients [Lavín et al., 1995] and cool SST are present year round [Paden et al., 1991; Soto-Mardones et al., 1999] in this area.

[19] Acknowledgments. This study was partially financed by CONACyT grant 44055 and CICESE's regular budget. Critical review of Manuel López, Julio Candela, and Miguel Lavín is greatly appreciated.

\section{References}

Backhaus, J. O. (1985), A three-dimensional model for the simulation of shelf sea dynamics, Dtsch. Hydrogr. Z., 38, 165-187.

Badan-Dangon, A., M. C. Hendershott, and M. F. Lavin (1991), Underway Doppler current profiles in the Gulf of California, Eos Trans. AGU, 72, 209.

Bray, N. A. (1988), Thermohaline circulation in the Gulf of California, J. Geophys. Res., 93, 4993-5020.

de Young, B., and S. Pond (1988), The deepwater exchange cycle in Indian Arm, British Columbia, Estuarine Coastal Shelf Sci., 26, 285-308.

Griffin, D. A., and P. H. LeBlond (1990), Estuarine/ocean exchange controlled by spring-neap tidal mixing, Estuarine Coastal Shelf Sci., 30, $275-297$.
Lavín, M. F., G. Gaxiola-Castro, J. M. Robles, and K. Ritcher (1995), Winter water masses and nutrients in the northern Gulf of California, J. Geophys. Res., 100, 8587-8605.

Lavín, M. F., R. Durazo, E. Palacios, M. L. Argote, and L. Carrillo (1997), Lagrangian observations of the circulation in the northern Gulf of California, J. Phys. Oceanogr., 27, 2298-2305.

LeBlond, P. H., H. Ma, F. Doherty, and S. Pond (1991), Deep and intermediate water replacement in the Strait of Georgia, Atmos. Ocean, 29, $288-312$.

López, M., and J. García (2003), Moored observations in the northern Gulf of California: A strong bottom current, J. Geophys. Res., 108(C2), 3048, doi:10.1029/2002JC001492.

López, M., J. Candela, and M. L. Argote (2006), Why does the Ballenas Channel have the coldest SST in the Gulf of California?, Geophys. Res. Lett., 33, L11603, doi:10.1029/2006GL025908.

Marinone, S. G. (2003), A three-dimensional model of the mean and seasonal circulation of the Gulf of California, J. Geophys. Res., 108(C10), 3325, doi:10.1029/2002JC001720.

Marinone, S. G., and M. F. Lavín (2003), Residual flow and mixing in the large islands region of the central Gulf of California, in Nonlinear Processes in Geophysical Fluid Dynamics, edited by O. U. Velasco Fuentes et al., pp. 213-236, Springer, New York.

Mateos, E., S. G. Marinone, and M. F. Lavín (2006), Role of tides and mixing in the formation of an anticyclonic gyre in San Pedro Mártir basin, Gulf of California, Deep Sea Res., Part II, 53, 60-76.

Paden, C. A., M. R. Abbot, and C. Winant (1991), Tidal and atmospheric forcing of the upper ocean in the Gulf of California: 1. Sea surface temperature variability, J. Geophys. Res., 96, 18,337-18,359.

Soto-Mardones, L., S. G. Marinone, and A. Parés-Sierra (1999), Time and spatial variability of sea surface temperature in the Gulf of California, Cienc. Mar., 25(1), 1-30.

Yao, T., S. Pond, and L. A. Mysak (1982), Low-frequency subsurface current and density fluctuations in the Strait of Georgia, Atmos. Ocean, $20,340-356$.

S. G. Marinone, Department of Physical Oceanography, CICESE, P.O. Box 434844, San Diego, CA 92143-4844, USA. (marinone@cicese.mx) 